\title{
Analysis
}

\section{The role of antibody tests for COVID-19 in primary care}

\section{INTRODUCTION}

The control of coronavirus 2019 disease (COVID-19) relies on implementing an effective testing and tracing strategy; the ideal would be a move to using rapid pointof-care tests (POCTs) in the community, to detect both active infections and to identify those already immune, as being tested in Liverpool.1 To date, largely laboratorybased virology testing (reverse transcription polymerase chain reaction (PCR) to detect viral ribonucleic acid from naso/ oropharyngeal swabs) remains the gold standard for diagnosis. The role of COVID-19 antibody testing is limited, with few studies published about the diagnostic accuracy of POCTs that might be used in primary care. This article aims to summarise the current state of knowledge about the potential role of COVID-19 antibody testing in primary care.

\section{THE ROLE OF ANTIBODY TESTING IN COVID-19 INFECTION}

Following infection, we develop immunoglobulins (lg) against SARS-CoV-2 proteins, including the diagnostically important nucleoprotein and/or spike proteins ( $\mathrm{N}$ - and S-proteins, respectively). The median time of detection of antiSARS-CoV-2 lgG is day 14 post-onset of symptoms (POS) (for IgM and IgA it is day 5), and it is detectable in $90 \%$ of individuals by then. ${ }^{2,3}$ Anti-N-protein immunoglobulin class $G(\lg G)$ is the most sensitive current target for serological detection, albeit its combined detection with anti-S improves sensitivity. ${ }^{4-6} \lg \mathrm{A}$ antibodies, implicated in mucosal surface defence, are detectable from the first day POS. ${ }^{3}$

A waning in $\lg G$ response has been reported, ${ }^{7}$ with potentially severe implications for long-term immunity depending upon the alternative effectiveness of memory T-cell-mediated immunity. There are suggestions that seropositive individuals are only at a lower risk of re-infection compared with seronegative individuals. ${ }^{8}$ There is no definitive evidence present about the protective effect, if any, of anti-SARS-CoV-2 antibody against reinfection and/or COVID-19 disease. Individuals previously infected with COVID19 can serorevert and some who have seroconverted do not necessarily stop shedding the virus following the antibody response. . $^{910}$

\section{'The sole reliance on virological testing is a limiting factor for an effective national testing strategy.}

Limitations of virology testing include the variable rate of viral detection dependent upon the timing of the test, ${ }^{11}$ the potential scarcity in the availability of test materials, ${ }^{12}$ the potential degradation of specimen quality during transport to testing facilities, the time delay between testing and results, and the need for skilled staff, as well as the infrastructure and equipment requirements. Antibody testing presents a cheaper $^{13}$ strategy to ease the testing burden, and to detect prior infection of individuals who may not have been tested or recorded for surveillance purposes because of mild symptoms or a lack thereof. Methods of testing include enzymelinked immunosorbent assays (ELISA), chemiluminescence immunoassays (CLIA), and, the only potential POCT, lateral flow immunoassays (LFIA). The rapid development of antibody testing has resulted in a sizeable number of potential Ig-method combinations that are yet to be fully tested and reproducibly reviewed.

\section{DETERMINING THE UTILITY OF ANTIBODY TESTING IN PRIMARY CARE}

To date, we have not identified any studies on the accuracy of antibody tests within a primary care setting. We searched MEDLINE, the COVID-19 Open Access
Project (COAP) Living Database, which collated articles from EMBASE, pre-prints from medRxiv and bioRxiv, and Public Health England (PHE) online information. The diagnostic accuracy of antibody testing and the extent of their applicability within primary care settings are not known. We have therefore collated the findings from a Cochrane Systematic Review and a systematic review and meta-analysis by

\section{THE CURRENT STATE OF KNOWLEDGE}

Our literature review summarises the optimal immunoglobulin(s) assays, method, and timing.

Stratification of pooled sensitivity and specificity by the serological test method and Ig classes should inform the clinical diagnostic utility of tests. The point estimates show corroborating results supporting CLIA methods with the highest statistically significant point estimate for all $\lg$ isotypes assayed, and especially for IgG/IgM combinations. ${ }^{14}$ Specificity for all methods was high, with the lowest point estimate at $94.1 \% .^{14}$

Diagnostic accuracy is determined by the time POS that the patient presents. Point estimates of pooled sensitivity stratified by lg classes are shown in Table 1,14 with Lisboa Bastos et al. ${ }^{6.14}$

Table 1. Pooled sensitivity estimates stratified by time POS

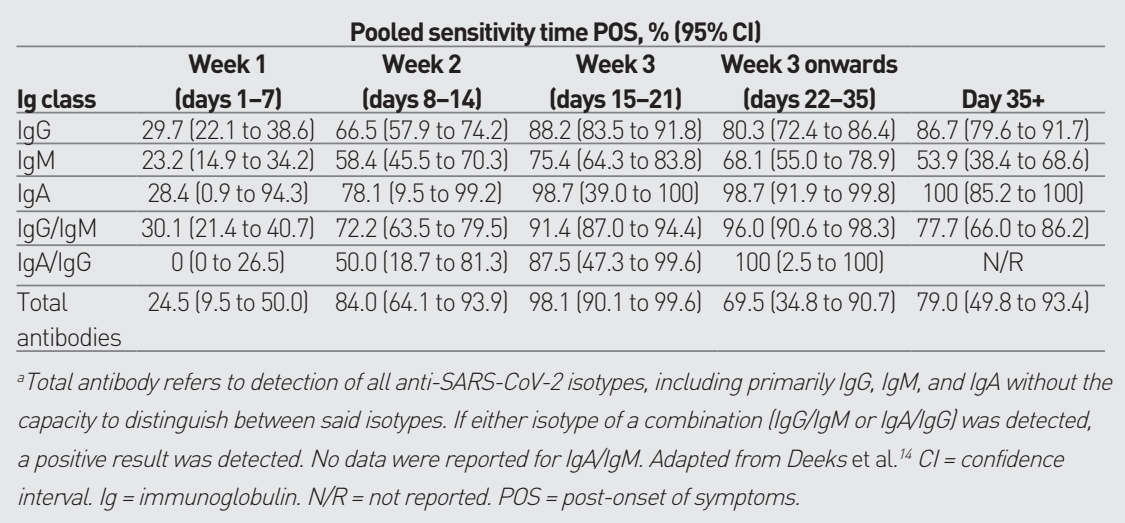




\section{Table 2. Pooled sensitivity estimates of serological test methods for}

$\lg M$ and $\lg G$ stratified by time POS

\begin{tabular}{|c|c|c|c|c|}
\hline \multirow[b]{2}{*}{ Ig class } & \multirow{2}{*}{$\begin{array}{c}\text { Test } \\
\text { method }\end{array}$} & \multicolumn{3}{|c|}{ Pooled sensitivity time POS, $\%(95 \% \mathrm{CI})$} \\
\hline & & Week 1 & Week 2 & Week 3 and later \\
\hline \multirow[t]{3}{*}{$\lg M$} & CLIA & 50.3 (10.9 to 81.2) & $74.3(16.1$ to 99.4$)$ & 90.6 (51.8 to 99.4) \\
\hline & ELISA & $26.7(15.6$ to 35.6$)$ & $57.6(15.9$ to 88.2$)$ & 78.4 (54.1 to 91.9 ) \\
\hline & LFIA (POCT) & $25.13(16.3$ to 31.1$)$ & $51.8(30.3$ to 69.6$)$ & $69.9(58.4$ to 79.9$)$ \\
\hline \multirow[t]{3}{*}{$\lg G$} & CLIA & 53.2 (28.7 to 67.6$)$ & 85.4 (48.1 to 98.1$)$ & 98.9 (86.9 to 100) \\
\hline & ELISA & $23.7(12.7$ to 38.1$)$ & $65.3(46.3$ to 79.4$)$ & 82.1 (76.4 to 89.0 ) \\
\hline & LFIA (POCT) & 13.4 (4.7 to 29.6$)$ & 50.1 (24.8 to 77.0$)$ & 79.7 (71.4 to 86.9 ) \\
\hline
\end{tabular}

${ }^{a}$ Adapted from Lisboa Bastos et al. ${ }^{6} \mathrm{Cl}=$ confidence interval. $\mathrm{CLIA}=$ chemiluminescence immunoassay. ELISA = enzyme-linked immunosorbent assay. $1 \mathrm{~g}=$ immunoglobulin. LFIA = lateral flow immunoassay. POCT $=$ point-of-care tests. POS = post-onset of symptoms.

corroborating evidence for $\lg M$ and $\lg G$ tests in Table 2. ${ }^{6}$ Point specificities were high and ranged between $98.5 \%(95 \% \mathrm{Cl}=97.2$ to 99.2) and $99.8 \%(95 \% \mathrm{Cl}=98.9$ to 100$]]^{14}$ Pooled sensitivities were lower in the first and second week POS compared with the third week or later. For $\lg M$ and $\lg G$, the CLIA method in week 3 POS had the highest point sensitivity estimate. The CLIA IgG test method had the highest point sensitivity at $98.9 \%$. Nonetheless, point sensitivity estimates in week 2 or week 3 for any other method bar CLIA would misclassify a significant portion of true COVID-19-positive patients. The evidence for $\lg G$ and $\lg M$ was reported to be particularly strong as it was based upon several thousands of nonCOVID samples. ${ }^{14} \lg G$ appears to be the only reliable indicator once any discernible time (>14 days) has passed. Diagnostic testing within 2 weeks POS should ideally be a PCR test.

Conclusions from findings derived from pooled samples are limited as the methodologies of the reviews pooled multiple cross-sectional studies, tracking different groups of participants over time with different test methods. ${ }^{14}$ This makes it more difficult to identify individual tests that may perform well.

PHE has carried out laboratory evaluations of commercial antibody tests using samples from community cases with mild disease presentations (Table 3). ${ }^{15}$ Despite previous seroprevalence studies reporting that, in adults aged $>50$ years,
$90 \%$ had antibodies to all four common circulating coronaviruses; ${ }^{16}$ the high specificities reported provide indirect evidence that there is little cross-reactivity with these seasonal coronaviruses. The Roche Elecsys Anti-COVID-19 and Abbott COVID-19 IgG assays have been assessed and validated by PHE, potentially enabling widespread adoption. Both tests had the highest point sensitivity estimates of all assays during the third week POS. Promisingly, their characteristics corroborate with the CLIA methods profiles, and the antibodies tested (Abbott: IgG; Roche: IgG/lgMl demonstrate relatively high point sensitivities. However, they fail to fulfil the UK Medicines and Healthcare products Regulatory Authority threshold of clinical sensitivity and specificity $>98 \%$ each for accreditation as valid POCTs. ${ }^{17}$ Despite limitations in diagnostic accuracy, a positive antibody test can be an acceptable alternative to a negative PCR result in suspected cases with supporting clinical evidence of COVID-19 where patients are $<14$ days POS for retrospective diagnosis as a confirmed case. ${ }^{18}$

\section{CONCLUSIONS AND RECOMMENDATIONS}

Antibody tests have limited utility in the acute diagnosis of COVID-19. However, they retain value in informing sero-epidemiological surveillance. We are yet to discover their role in mass population testing.

Table 3. Summary table of PHE-reported sensitivities and specificities ${ }^{a}$

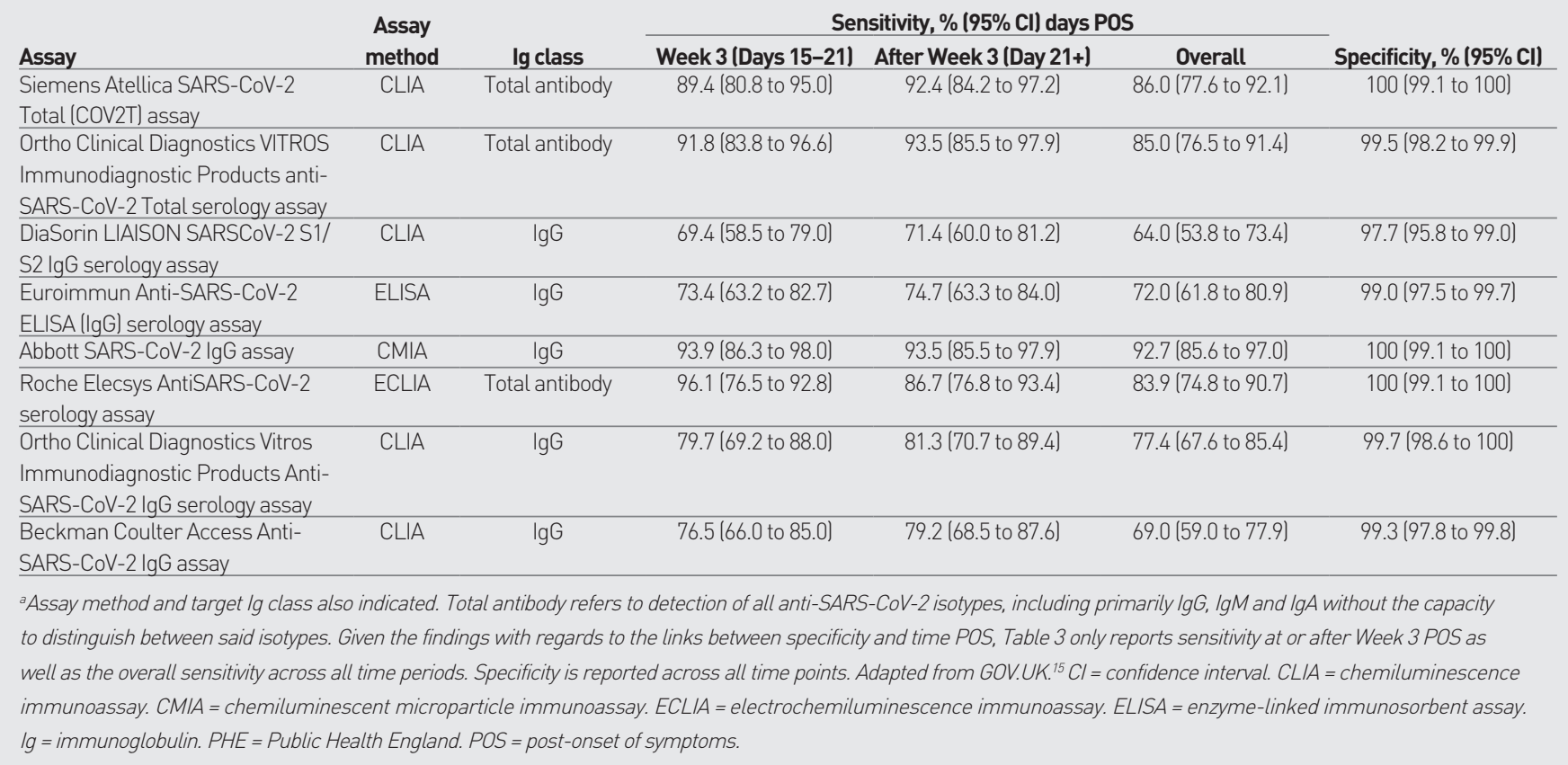




\section{STRENGTHS AND LIMITATIONS FOR USE IN PRIMARY CARE}

The high specificity in many of the tests is promising for potential serosurveillance applications $^{14}$ to prevent the facilitation of widespread transmission through a premature easing of public health restrictions. However, the use of prepandemic samples to establish specificity has introduced questions surrounding their validity and their relevance in the current climate. ${ }^{19}$ Thus, there are applicability concerns about the implications for the use of POCT specimens and antibody tests in general within primary care settings.

\section{IMPLICATIONS}

The sole reliance on virological testing is a limiting factor for an effective national testing strategy. Antibody testing in parallel with virology testing may be appropriate.

Antibody tests are limited by their inability to distinguish between current or past infection. Shorter-term triage of symptomatic patients and close contacts of confirmed cases in community settings within a week POS may be facilitated by rapid antibody testing for $\lg M$, given its early transient rise, with high specificity. ${ }^{19}$ As discussed, in instances of scarcity of resources or skilled staff with the required sampling techniques, ${ }^{11}$ or given the time delay between testing and the resulting implications for individuals' lives, the logistical burdens and socioeconomic impacts arising from when virology testing capabilities are limited may be eased by antibody testing. The use of IgM or total antibody tests for symptomatic patient diagnosis has improved case detection sensitivity. ${ }^{19}$ People with negative antibody tests where there is clinical suspicion could go on to have a virological test. Serological diagnosis is important for patients with mild to moderate illness. ${ }^{11}$ Serological confirmation may also play an important role in low-prevalence communities or immediately following lockdown measures when diagnostic accuracy of virological testing may be adversely affected by low levels of circulating virus. ${ }^{20,21}$ The two PHEvalidated Roche and Abbott antibody tests fit the profile for utilisation in the UK with

\section{"At best, the results of antibody tests will inform the proportion of the practice workforce who are potentially immune.}

the Roche test better suited, where the patient presents week $3 \mathrm{POS}$ and the Abbott test for patients presenting week 3 onwards (>day 21) POS

Follow-up testing has been proposed to tackle the shortcomings of accurate serological diagnosis. ${ }^{22}$ With an approximate $6 \%$ prevalence as per recent reports, ${ }^{23}$ should the Euroimmun assay $183.0 \%$ sensitivity, 99.3\% specificity) (as utilised for testing for the PHE Weekly COVID-19 Surveillance Reports) be used followed by a more specific test such as the Abbott assay $(93.9 \%$ sensitivity, $100 \%$ specificity) as a confirmatory test, the positive predictive value would increase from $88.3 \%$ to $100 \%$.

For the wider asymptomatic population, any test is suitable as the majority of antibody tests have very high negative predictive values (NPVs), even with the lowest specificity of $94.1 \%$ resulting in a $98.9 \%$ NPV. However, a follow-up IgG CLIA antibody test at least after 5 weeks should be carried out to ensure that the first negative result was not due to sample collection too soon after asymptomatic infection, or due to an absence of a detectable immune response las in immunosuppressed patients). A person with a negative test may nonetheless possess cellular (T-lymphocyte) immunity.

Ongoing research within this rapidly developing area, including the rapid test diagnostic evaluation in the community study (RAPTOR), ${ }^{24}$ may eventually elucidate how diagnostically valid POCTs can be introduced into the primary care workflow, for individual patient benefit rather than population monitoring, possibly in a complementary strategy incorporating virology testing as well as the current antigen POCTs undergoing evaluation.

Serosurveillance presents opportunities to screen recovered patients for potential convalescent plasma donation, monitor the immune responses against vaccines, indicate the dynamics of transmission, and to determine when, or if, we reach a state of herd immunity; all of which will be critical in surmounting this debilitating pandemic.

\section{FUTURE OUTLOOK}

Achieving the best balance of sensitivity and specificity for robust diagnostic application has been challenging so far. At best, the results of antibody tests will inform the proportion of the practice workforce who are potentially immune. Practices should continue advising patients to maintain protective measures until the length and strength of long-term immunity is known. Given the uncertainty of the antibody tests, practices would not be well advised to solely rely on and purchase the tests themselves. However, where rapid virology testing is not readily available, the following recommendations suggest which type of antibody tests may be used:

- <week 3 POS - PCR (virology swab); or lgG/lgM followed by virology in negative cases with clinical suspicion especially $<$ week 2 POS:

- week 3 POS - total antibodies or lgG/lgM combination CLIA;

- week 3 onwards POS - lgG, lgG/lgM, or total antibodies CLIA; and

- $>5$ weeks POS - IgG CLIA.

Antibody tests are an emergent and important part of the management of the COVID-19 pandemic. It is important that we understand their limitations alongside their strengths.

\section{Azmaeen Zarif,}

NIHR Intern and Medical Student, Nuffield Department of Primary Care Health Sciences, University of Oxford, Oxford.

\section{Dylan McGagh,}

Medical Student, Nuffield Department of Primary Care Health Sciences, University of Oxford, Oxford.

Uy Hoang,

Research Fellow, Nuffield Department of Primary Care Health Sciences, University of Oxford, Oxford. 


\section{Simon de Lusignan}

Professor of Primary Care and Clinical Informatics, Nuffield Department of Primary Care Health Sciences, University of Oxford, Oxford.

\section{Provenance}

Freely submitted; externally peer reviewed.

\section{Competing interests}

Simon de Lusignan through his academic appointment at the University of Oxford is an investigator in the RAPTOR study, and Director of
RCGP Research and Surveillance Centre (RSC), which will host this study. Simon de Lusignan has been involved in POCT studies in influenza part-supported by Abbott and Roche, through his university affiliation. The other authors have declared no competing interests.

\section{Acknowledgements}

We would like to thank Prof. John V Parry (Public Health England) and Dr Brian Nicholson (University of Oxford) for their detailed review and comments.

DOI: https://doi.org/10.3399/bjgp21X715169

\section{ADDRESS FOR CORRESPONDENCE}

Simon de Lusignan

Professor of Primary Care and Clinical Informatics, Nuffield Department of Primary Care Health Sciences, Eagle House, Walton Well Road, Oxford OX2 6ED, UK

Email: simon.delusignanaphc.ox.ac.uk

\section{REFERENCES}

1. lacobucci G. Covid-19: mass population testing is rolled out in Liverpool. BMJ 2020; 371: m4268. https://www.bmj.com/lookup/ doi/10.1136/bmj.m4268 (accessed 26 Jan 2021).

2. Zhao J, Yuan Q. Wang $\mathrm{H}$, et al. Antibody responses to SARS-CoV-2 in patients with novel coronavirus disease 2019. Clin Infect Dis 2020; 71(16): 2027-2034. https://pubmed.ncbi. nlm.nih.gov/32221519/ laccessed 26 Jan 2021).

3. Guo L, Ren L, Yang S, et al. Profiling early humoral response to diagnose novel coronavirus disease (COVID-19). Clin Infect Dis 2020; 71(15): 778-785. https://pubmed.ncbi. nlm.nih.gov/32198501/ (accessed 26 Jan 2021).

4. Burbelo PD, Riedo FX, Morishima C, et al. Detection of nucleocapsid antibody to SARSCoV-2 is more sensitive than antibody to spike protein in COVID-19 patients. medRxiv 2020; Apr 24: http://uww.ncbi.nlm.nih.gov/ pubmed/32511445 (accessed 26 Jan 2021).

5. Chang MS, Lu YT, Ho ST, et al. Antibody detection of SARS-CoV spike and nucleocapsid protein. Biochem Biophys Res Commun 2004; 314(4): 931-936. https://pubmed.ncbi.nlm.nih gov/14751221/ (accessed 26 Jan 2021).

6. Lisboa Bastos M, Tavaziva G, Abidi SK, et al. Diagnostic accuracy of serological tests for covid-19: systematic review and meta-analysis. BMJ 2020; 370: m2516. https://pubmed.ncbi. nlm.nih.gov/32611558/ (accessed 26 Jan 2021).

7. Seow J, Graham C, Merrick B, et al. Longitudinal evaluation and decline of antibody responses in SARS-CoV-2 infection. medRxiv 2020; Jul 11: http://medrxiv.org/content/ear ly/2020/07/11/2020.07.09.20148429.abstract laccessed 26 Jan 2021)

8. Theel ES, Slev P, Wheeler S, et al. The role of antibody testing for SARS-CoV-2: is there one? J Clin Microbiol 2020; 58(8): e00797-20. https:// pubmed.ncbi.nlm.nih.gov/32350047/ laccessed 26 Jan 2021).

9. Shen C, Wang Z, Zhao F, et al. Treatment of 5 critically ill patients with COVID-19 with convalescent plasma. JAMA 2020; 323(16): 1582-1589. https://jamanetwork.com/journals/ jama/fullarticle/2763983 laccessed 26 Jan 2021).

10. Liu WD, Chang SY, Wang JT, et al. Prolonged virus shedding even after seroconversion in a patient with COVID-19. J Infect 2020 81(2): 318-356. https://pubmed.ncbi.nlm.nih. gov/32283147/ (accessed 26 Jan 2021).

11. Sethuraman N, Jeremiah SS, Ryo A. Interpreting diagnostic tests for SARS-CoV-2 JAMA 2020; 323(22): 2249-2251. https:// pubmed.ncbi.nlm.nih.gov/32374370/ laccessed 26 Jan 2021)

12. American Society for Microbiology. ASM expresses concern about coronavirus test reagent shortages. 2020; Mar 10: https:// asm.org/Articles/Policy/2020/March/ASM Expresses-Concern-about-Test-ReagentShortages (accessed 26 Jan 2021).

13. Al-Muharraqi MA. Testing recommendation for COVID-19 (SARS-CoV-2) in patients planned for surgery - continuing the service and 'suppressing' the pandemic. $\mathrm{Br} J \mathrm{Oral}$ Maxillofac Surg 2020; 58(5): 503-505. https:// pubmed.ncbi.nlm.nih.gov/32307131/ laccessed 26 Jan 2021).

14. Deeks JJ, Dinnes J, Takwoingi Y et al. Antibody tests for identification of current and past infection with SARS-CoV-2. Cochrane Database Syst Rev 2020; 6(6): CD013652. https://pubmed. ncbi.nlm.nih.gov/32584464/ laccessed 26 Jan 2021)

15. GOV.UK. COVID-19: laboratory evaluations of serological assays. 2020. https://mww.gov.uk/ government/publications/covid-19-laboratoryevaluations-of-serological-assays laccessed 26 Jan 2021)

16. Gorse GJ, Patel GB, Vitale JN, O'Connor TZ. Prevalence of antibodies to four human coronaviruses is lower in nasal secretions than in serum. Clin Vaccine Immunol 2010; 17(12): 1875-1880. https://pubmed.ncbi.nlm.nih. gov/20943876/ (accessed 26 Jan 2021).

17. Medicines \& Healthcare products Regulatory Agency. Target product profile: enzyme Immunoassay (EIA) Antibody tests to help determine if people have antibodies to SARS
CoV-2. 2020. https://unw.gov.uk/government/ publications/how-tests-and-testing-kits-forcoronavirus-covid-19-work/target-productprofile-enzyme-immunoassay-eia-antibodytests-to-help-determine-if-people-haveantibodies-to-sars-cov-2 laccessed 26 Jan 2021).

18. National Health Commission \& State Administration of Traditional Chinese Medicine. Diagnosis and treatment protocol for COVID-19 (trial version 7). 2020. https://umw.chinadaily. com.cn/pdf/ laccessed 2 Feb 2021)

19. Peeling RW, Wedderburn CJ, Garcia PJ, et al. Serology testing in the COVID-19 pandemic response. Lancet Infect Dis 2020; 20(9): e245-e249. https://pubmed.ncbi.nlm.nih. gov/32687805/ (accessed 26 Jan 2021).

20. Ripperger TJ, Uhrlaub JL, Watanabe M, et al. Orthogonal SARS-CoV-2 serological assays enable surveillance of low-prevalence communities and reveal durable humoral immunity. Immunity 2020; 53(5): 925-933.e4. https://pubmed.ncbi.nlm.nih.gov/33129373/ laccessed 26 Jan 2021).

21. Behrens GMN, Cossmann A, Stankov MV, et al. Strategic anti-SARS-CoV-2 serology testing in a low prevalence setting: the COVID-19 Contact (CoCo) Study in Healthcare Professionals. Infect Dis Ther 2020; 9(4): 837-849. https://pubmed. ncbi.nlm.nih.gov/32886335/ laccessed 26 Jan 2021).

22. Duong YT, Wright CG, Justman J. Antibody testing for coronavirus disease 2019: not ready for prime time. BMJ 2020; 370: m2655. https://uww.bmj.com/content/370/bmj.m2655 laccessed 26 Jan 2021).

23. GOV.UK. National COVID-19 surveillance reports.2020. https://mww.gov.uk/government/ publications/national-covid-19-surveillancereports (accessed 26 Jan 2021).

24. Hobbs RF, Nicholson BD, Hayward G, et al. Expanding national RAPid community Test evaluation capacity fOR COVID-19. Oxford, 2020. https://www.condor-platform.org/files/raptor/ raptor-protocol-version-1-1.pdf laccessed 26 Jan 2021). 